\title{
Factor Market Distortions Across Time, Space and Sectors in China
}

\author{
Loren Brandt, Trevor Tombe and Xiaodong Zhu ${ }^{1}$
}

November 28, 2010

$1_{\text {University of Toronto. Emails: brandt@chass.utoronto.ca, trevor.tombe@utoronto.ca, xzhu@chass.utoronto.ca }}$ 


\begin{abstract}
In this paper we measure the distortions in the allocation of labor and capital across provinces and sectors in China for the period 1985-2007. Most existing studies have measured factor market distortions by using some index of dispersion in individual factor returns. However, the map between these dispersion measures and the efficiency loss due to distortions is not clear, especially when there is more than one factor. In this paper, we follow Hsieh and Klenow (2009)'s strategy by measuring the factor market distortions as the reduction in aggregate TFP due to distortions. We extend their analysis by decomposing the overall distortions into between-province and within-province inter-sectoral distortions. We find: (1) For the period between 1985 and 2007, the distortions in factor allocation reduced aggregate TFP by about $31 \%$ on average, with the within-province distortions accounting for more than half of the reduction; (2) the measure of between-province distortions was relatively constant over the period; (3) the measure of within-province distortions declined between 1985 and 1997, contributing to $0.96 \%$ TFP growth per year, but then increased significantly in the last ten years, reducing the aggregate TFP growth rate by $1.41 \%$ a year; and (4) almost all of the within-province distortions can be accounted for by the misallocation of capital between the state and the non-state sectors.
\end{abstract}




\section{Introduction}

Some of the rapid growth that China has enjoyed the last three decades has likely come from reductions in distortions that we expect to accompany the processes of economic transition and development. In this paper, we measure the impact on aggregate TFP of distortions in factor allocation across provinces and sectors in China and investigate the contribution of changes in these distortions to aggregate TFP growth.

The period up through the early to mid-1990s in China is often characterized as one of important barriers and restrictions on resource mobility. In addition to restrictions through the hukou system on the movement (both intra- and inter-provincial) of labor out of the countryside (Chan, Henderson and Tsui, 2008), local protectionism and trade barriers also likely impeded the inter-regional flow of goods (Young, 2000; Poncet, 2003). The likely costs of these distortions were reinforced by those on the flow of capital across regions (BoyreauDebray and Wei 2005, Dollar and Wei, 2007).

The general presumption is that many of these barriers have been significantly relaxed the last decade and a half. For example, migrant labor flows are now in upwards of 150 million, and there have been significant increases in inter-regional trade accompanying reduction in barriers (Holz, 2009). Things are less certain with respect to the behavior of capital flows, however. Reform in the banking system may be helping to allow a more efficient regional allocation of capital through the inter-bank market and other channels. Possibly offsetting some of this is the fact that a significant amount of investment resources continues to be directed by the state to state-owned firms and activity, e.g. infrastructure, or to activities in which the local state is often a beneficiary, e.g. real estate development through land sales. This suggests significant differences in the returns to capital between the state and non-state, which have recently been documented by Brandt and Zhu (2010)). Since the late 1990s, there have also been efforts, through such policies as the Xibu Kaifa (Develop the Great West), to eliminate perceived policy biases in favour of coastal provinces by reallocating investment resources towards the interior regions.

In figures 1 and 3, we plot the returns to labor and capital for the state and the nonagricultural nonstate sectors in 27 provinces of China over the period from 1985 to 2007. Two observations are noteworthy. First, within each province, there is a large gap in returns

to capital between the state and the non-state sectors. However, within each sector, the cross-province differences in returns to capital are relatively small. And second, in contrast, there are large cross-province differences in returns to labor, but relatively small cross-sector 
difference within each province. In a frictionless economy, the returns to labor and capital would be equalized across province and sectors. The observed differences in returns suggest that factor allocation in China is still highly distorted.

How should one measure the distortions in factor allocation? Existing studies of China's factor market distortions have used separate measures of dispersion in the individual returns to labor and capital. Boyreau-Debray and Wei (2003), Dollar and Wei (2005), and Bai, Hsieh and Qian (2006), for example, examine the dispersion in returns to capital. Gong and Xie (2006) and Zhang and Tan (2007) look at the dispersions in returns to labor as well as in returns to capital, but separately. While these dispersion measures are informative about factor market distortions, there is no clear link between these measures and the aggregate TFP. In this study, we follow the strategy of Hsieh and Klenow (2009) by examining the overall factor market distortions and linking them to aggregate TFP. More specifically, we measure the impact of factor market distortions as the reduction in aggregate TFP due to the distortions. This approach allows us to identify the sources of factor market distortions but also to measure the impact of these distortions on aggregate efficiency in the economy. While Hsieh and Klenow investigate the misallocation of factors across manufacturing firms, we focus on the distortions in the allocation of factors across provinces and sectors.

We find that:

- On average, the misallocation of factors across provinces and sectors resulted in a $31 \%$ reduction of aggregate TFP, with the within-province distortions accounting for more than half of the total reductions.

- The size of between-province distortions was relatively constant over the entire period.

- The measure of within-province distortions declined sharply between 1985 and 1997, contributing to $0.96 \%$ TFP growth per year, but then increased significantly in the last ten years, reducing the aggregate TFP growth rate by $1.41 \%$ a year.

- Almost all of the within-province distortions was due to the misallocation of capital between the state and the non-state sectors.

Our analysis in this paper is related to a recent literature that links the misallocation of factors, either across sectors, or across firms within a sector, to aggregate productivity. 
Gollin, Parente and Rogerson (2004), Restuccia et. al. (2007) and Vollrath (2009) analyze the sectoral dimension while Banerjee and Duflo (2005); Restuccia and Rogerson (2008); Alfaro et. al. (2008), Bartelsman et. al (2008), Guner et. al. (2008) and Hsieh and Klenow (2009) focus on the misallocation across firms.

The rest of the paper is organized as follows. In Section 2, we present the theoretical framework for measuring factor market distortions and in Section 3, discuss data used for empirical analysis. We present the main empirical results in Section 4 and in the last section provide the concluding remarks.

\section{A Framework for Measuring Factor Market Distortions}

Consider an economy with $m$ provinces, indexed by $i=1, \ldots, m$, and two sectors, state and non-state, indexed by $j=n, s$, respectively. We assume Cobb-Douglas production technologies with constant factor income shares in all provinces and sectors:

$$
Y_{i j}=A_{i j} L_{i j}^{a} K_{i j}^{1-a}, 0<a<1 .
$$

We also assume that provincial GDP is a CES aggregate of goods produced in the two sectors and the aggregate GDP is a CES aggregate of provincial GDPs. Thus,

$$
Y_{i}=\left(Y_{i n}^{1-\phi}+Y_{i s}^{1-\phi}\right)^{\frac{1}{1-\phi}}
$$

and

$$
Y=\left(\sum_{i=1}^{m} Y_{i}^{1-\sigma}\right)^{\frac{1}{1-\sigma}}
$$

Here $\phi^{-1}$ and $\sigma^{-1}$ are the elasticities of substitution among sectors and provinces, respectively. To avoid the result that, without distortions, all factors should be allocated to the province and sector with the highest TFP level, we will assume that the goods across sectors and regions are imperfect substitutes, i.e., positive $\phi$ and $\sigma{ }^{1}$

Let

$$
L_{i}=L_{i n}+L_{i s}, K_{i}=K_{i n}+K_{i s}
$$

\footnotetext{
${ }^{1}$ Alternatively, we could have assumed these goods are perfect substitutes but there are diminishing returns.
} 
be the employment and capital stock in province $i$ and let

$$
\begin{gathered}
l_{j \mid i}=\frac{L_{i j}}{L_{i}}, k_{j \mid i}=\frac{K_{i j}}{K_{i}} \\
l_{i}=\frac{L_{i}}{L}, k_{i}=\frac{K_{i}}{K}
\end{gathered}
$$

be the shares of employment and capital. Then, the provincial and aggregate TFP can be written as follows:

$$
\begin{gathered}
A_{i}=\left[Y_{i s}^{1-\phi}+Y_{i n}^{1-\phi}\right]^{\frac{1}{1-\phi}} /\left(L_{i}^{a} K_{i}^{b}\right)=\left[\left(A_{i s} l_{s \mid i}^{a} k_{s \mid i}^{b}\right)^{1-\phi}+\left(A_{i n} l_{n \mid i}^{a} k_{n \mid i}^{b}\right)^{1-\phi}\right]^{\frac{1}{1-\phi}} \\
A=\left[\sum_{i=1}^{m} Y_{i}^{1-\sigma}\right]^{\frac{1}{1-\sigma}} /\left(L^{a} K^{b}\right)=\left[\sum_{i=1}^{m}\left(A_{i} l_{i}^{a} k_{i}^{b}\right)^{1-\sigma}\right]^{\frac{1}{1-\sigma}}
\end{gathered}
$$

So, for a given set of sector-province specific TFPs, $A_{i j}, i=1, \ldots, m, j=n, s$, and given aggregate employment and capital stock, $L$ and $K$, the provincial and aggregate TFPs are determined by the allocation of labor and capital across sectors and provinces.

\subsection{Efficient Allocation}

As a benchmark, we first examine the efficient allocation of factors when there are no distortions in the economy. To do so, we consider the following social planner's problem:

$$
\max _{L_{i j}, K_{i j}} Y
$$

subject to (1), (2), (3) and

$$
\begin{aligned}
& \sum_{i, j} L_{i j}=L \\
& \sum_{i, j} K_{i j}=K
\end{aligned}
$$

Then, we have

Proposition 1. For any given $L$ and $K$, the allocation of labor and capital that maximizes the aggregate GDP is given by: 


$$
\begin{gathered}
\frac{L_{i j}}{L_{i}}=\frac{K_{i j}}{K_{i}}=\pi_{j \mid i}, \\
\frac{L_{i}}{L}=\frac{K_{i}}{K}=\pi_{i},
\end{gathered}
$$

where

$$
\begin{gathered}
\pi_{j \mid i}=\left(\frac{A_{i j}}{A_{i}^{*}}\right)^{\frac{1-\phi}{1-(1-\phi)(a+b)}}=\frac{A_{i j}^{\frac{1-\phi}{1-(1-\phi)(a+b)}}}{\sum_{j=1}^{n} A_{i j}^{\frac{1-\phi}{1-(1-\phi)(a+b)}}} \\
\pi_{i}=\frac{\left(A_{i}^{*}\right)^{\frac{1-\sigma}{1-(1-\sigma)(a+b)}}}{\sum_{i=1}^{m}\left(A_{i}^{*}\right)^{\frac{1-\sigma}{1-(1-\sigma)(a+b)}}}
\end{gathered}
$$

and

$$
A_{i}^{*}=\left[\sum_{j=n, s} A_{i j}^{\frac{1-\phi}{1-(1-\phi)(a+b)}}\right]^{\frac{1-(1-\phi)(a+b)}{1-\phi}}
$$

Proof: See Appendix.

Proposition 1 says that to maximize output, the share of capital and labor allocated to a sector and province should equal the TFP share in the sector and province, as defined by $\pi_{j \mid i}$ and $\pi_{i}$. Under the efficient allocation, it can be shown that $A_{i}^{*}$ is the provincial TFP and the aggregate TFP is

$$
A^{*}=\left[\sum_{i=1}^{m}\left(A_{i}^{*}\right)^{\frac{1-\sigma}{1-(1-\sigma)(a+b)}}\right]^{\frac{1-(1-\sigma)(a+b)}{1-\sigma}}
$$

For any given allocation of capital and labor, we can then measure the overall distortion and distortion in a province as the proportional loss in TFPs:

$$
\begin{gathered}
D=-\ln \left(A / A^{*}\right) \\
D_{i}=-\ln \left(A_{i} / A_{i}^{*}\right)
\end{gathered}
$$

If we simply want to know how distorted the actual allocation is relative to the efficient allocation, we could use the measures above and stop here. To understand the sources of the distortions, however, we need a model to help us first identify and then measure their impacts of these distortions. 


\subsection{Factor Allocation in a Competitive Market with Distortions}

An inefficient allocation of factors could be a direct result of factor market distortions or an indirect result of product market distortions. For example, even without factor market distortions, the factors could be inefficiently allocated to a province or sector with low TFP if protection in the product market artificially raises the province or sector's profits and therefore factor returns. We consider three distortions: province-specific taxes on output and sector-province specific taxes on capital and labor.

\subsubsection{Firms' Problem}

The profit maximization problem for producing the aggregate GDP, $Y$, is

$$
\max _{Y_{i}, i=1, \ldots, m}\left\{P\left(\sum_{i=1}^{m} Y_{i}^{1-\sigma}\right)^{\frac{1}{1-\sigma}}-\sum_{i=1}^{m} \tau_{i}^{y} P_{i} Y_{i}\right\}
$$

which implies the following first order conditions:

$$
\tau_{i}^{y} P_{i}=P\left(\frac{Y_{i}}{Y}\right)^{-\sigma}, i=1, \ldots, m
$$

Here $\tau_{i}^{y}$ is the tax on output produced in province $i$.

Similarly, the profit maximization problem of producing $Y_{i}$ is

$$
\max _{Y_{i s}, Y_{i n}}\left\{P_{i}\left(Y_{i s}^{1-\phi}+Y_{i n}^{1-\phi}\right)^{\frac{1}{1-\phi}}-P_{i s} Y_{i s}-P_{i n} Y_{i n}\right\}
$$

and the corresponding first-order conditions are

$$
P_{i j}=P_{i}\left(\frac{Y_{i j}}{Y_{i}}\right)^{-\phi}, j=s, n ; i=1, \ldots, m
$$

Note that we have assumed that there is no sector-specific output tax. We make this assumption because we do not have data to separately identify the taxes.

Using the definition of $Y_{i}$ and $Y$, it can be shown that

$$
P_{i}=\left(P_{i s}^{\frac{\phi}{\phi-1}}+P_{i n}^{\frac{\phi}{\phi-1}}\right)^{\frac{\phi-1}{\phi}}
$$


and

$$
P=\left(\sum_{i=1}^{m} \widehat{P}_{i}^{\frac{\sigma-1}{\sigma}}\right)^{\frac{\sigma}{\sigma-1}}
$$

Here,

$$
\widehat{P}_{i}=\tau_{i}^{y} P_{i}
$$

The stand-in firm's profit maximization problem in province $i$ and sector $j$ is

$$
\max _{K_{i j}, L_{i j}}\left\{P_{i j} A_{i j} L_{i j}^{a} K_{i j}^{1-a}-\tau_{i j}^{l} w L_{i j}-\tau_{i j}^{k} r K_{i j}\right\}
$$

Here, $w$ is the wage and $r$ is the rental price of capital, and $\tau_{i j}^{l}$ and $\tau_{i j}^{k}$ are taxes on labor and capital, respectively. The standard first-order conditions of the problem are:

$$
\begin{aligned}
a P_{i j} A_{i j} L_{i j}^{a-1} K_{i j}^{1-a} & =\tau_{i j}^{l} w \\
(1-a) P_{i j} A_{i j} L_{i j}^{a} K_{i j}^{-a} & =\tau_{i j}^{k} r
\end{aligned}
$$

Definition. For any given set of taxes $\left\{\tau_{i}^{y}, \tau_{i j}^{l}, \tau_{i j}^{k}\right\}_{i=1, \ldots, m ; j=n, s}$, the competitive equilibrium is a set of prices $\left\{P, P_{i}, P_{i j}\right\}_{i=1, \ldots, m ; j=n, s}$, output $\left\{Y, Y_{i}, Y_{i j}\right\}_{i=1, \ldots, m ; j=n, s}$, employments and capital stocks $\left\{L_{i j}, K_{i j}\right\}_{i=1, \ldots, m ; j=n, s}$ such that equations (1) to (12) hold. The corresponding set of shares of employment and capital stock $\left\{l_{i}, k_{i}, l_{j \mid i}, k_{j \mid i}\right\}_{i=1, \ldots, m ; j=n, s}$ is called the competitive allocation implemented by the set of taxes $\left\{\tau_{i}^{y}, \tau_{i j}^{l}, \tau_{i j}^{k}\right\}_{i=1, \ldots, m ; j=n, s}$.

Proposition 2. (1) For any set of positive taxes $\left\{\tau_{i}^{y}, \tau_{i j}^{l}, \tau_{i j}^{k}\right\}_{i=1, \ldots, m ; j=n, s}$, the competitive allocation implemented by the set of taxes exists and is unique. (2) For any allocation $\left\{l_{i}, k_{i}, l_{j \mid i}, k_{j \mid i}\right\}_{i=1, \ldots, m ; j=n, s}$, there exists a set of taxes such that the allocation is the competitive allocation implemented by the set of taxes. (3) Two sets of taxes $\left\{\tau_{i}^{y}, \tau_{i j}^{l}, \tau_{i j}^{k}\right\}_{i=1, \ldots, m ; j=n, s}$ and $\left\{\theta_{i}^{y}, \theta_{i j}^{l}, \theta_{i j}^{k}\right\}_{i=1, \ldots, m ; j=n, s}$ implement the same allocation if and only if there exists some positive constants, $\alpha, \beta$ and $\gamma$ such that $\theta_{i}^{y}=\alpha \tau_{i}^{y}, \theta_{i j}^{l}=\beta \tau_{i j}^{l}$ and $\theta_{i j}^{k}=\gamma \theta_{i j}^{k}$.

Proof: See Appendix.

\subsection{Identification of Distortion Taxes}

Proposition 2 shows that we can identify the distortion taxes (up to a proportional constant) from the actual allocation of labor and capital in the economy. 
More specifically, from equation (11) and (12), we have

$$
\begin{aligned}
\tau_{i j}^{l} & \propto \frac{P_{i j} Y_{i j}}{L_{i j}} \\
\tau_{i j}^{k} & \propto \frac{P_{i j} Y_{i j}}{K_{i j}}
\end{aligned}
$$

From Proposition 2 we know that factor allocation is not affected by any proportional change in taxes that is common across all province and sectors. So we can simply set the labor and capital taxes as average value products of labor and capital, respectively.

Given the labor and capital taxes, we then identify the output taxes by choosing $\tau_{i}^{y}$ such that the model implied employment share of province $i$ matches that in the data. ${ }^{2}$

\section{Data}

In order to generate the various measures of distortions within the Chinese economy that we derived in the previous section, sectoral and provincial data are required. Specifically, employment and real values of capital and output are required for both the state and non-state sectors of the non-agricultural economy. Unfortunately, official statistics are not provided for all the necessary variables and are provided with error for others. Consequently, we construct our own unique panel data set that incorporates both new variables and adjustments to currently reported variables. Overall, the data set is comprised of a panel of 27 provinces spanning 1985-2007 ${ }^{3}$. This section highlights the specific procedures and sources ${ }^{4}$.

First, consider the state and non-state employment data. Reported levels of total provincial employed persons ${ }^{5}$ are available from official sources. Adjustments to the data, however, are required for a number of reasons, including: (1) employment in shareholding corporations should be included in the state sector ${ }^{6}$; (2) the sum of provincial employment does not equal reported national employment; (3) employed persons include unemployed individuals and

\footnotetext{
${ }^{2}$ It can be shown that under the chosen output taxes, the model's implied share of capital stock of province i also matches that in the data.

${ }^{3}$ Chongqing is merged with Sichuan; Tibet, Hainan, and Hunan are excluded for missing data; 1978-1984 contains certain missing observations for certain provinces (Tianjin and Inner Mongolia, mainly) and so results will be displayed only for the 1983-2007 period.

${ }^{4}$ Tables of raw data are provided in an appendix to this paper.

5"Employed persons" is distinct from "staff and workers," which only cover urban workers.

${ }^{6}$ We include shareholding corporation employment within the state sector from 1993 onwards.
} 
excludes workers of age 15; and (4) reported primary sector employment is likely overstated. The adjustments to correct these issues require the use of the census micro-data records from 1982, 1990, 1995, 2000, and 2005. Differences between total provincial employment and reported national employment are distributed amongst the provinces in a manner consistent with the distribution of employment found in the census. Furthermore, we determine the provincial unemployment rate and fraction of workers age 15 with the census and adjust the yearbook statistics accordingly ${ }^{7}$. Next, reported provincial primary employment data are rescaled proportionately to match Brandt and Zhu $(2010)^{8}$. Finally, note that all adjustments to the employment data, with the exception of the shareholding corporation employment, are adjustments to the non-state sector. Briefly put, state sector employment is what is reported as State or Shareholding, and non-state sector employment is the residual from employment in the non-primary sector after subtracting the broadly defined state employment.

Second, sectoral capital stocks are constructed with a perpetual inventory method using the annual fixed asset investment data in the Statistical Yearbooks of China ${ }^{9}$. Investment data are deflated using the official province-specific price index of investment goods for the period 1993-2007. Prior to 1993, however, such provincial data are not available. Instead, we construct an out-of-sample forecast of principal asset deflators based on a regression of provincial asset price deflators on GDP deflators, the national asset price index, and year and province fixed effects. This estimate is conducted on all time periods for which provincial investment price data exist (normally 1992) and projected backwards based on the value of the covariates in the part. The price index series is then used to deflate the Fixed-Asset Investment series. Finally, non-agricultural investment is the fraction of fixed-asset investment that is not in the primary sector, where this fraction is determined by the primary sector fraction of Gross Fixed Capital Formation (data from Moeller (2006)) ${ }^{10}$. Assum-

\footnotetext{
${ }^{7}$ Data is interpolated between census years and trends forecasted adjustments between 1978-1982 and from 2006-2007. Note also that census employment counts may capture migrant workers in a way that Statistical Yearbooks do not.

${ }^{8}$ Specifically, the correction factor applied to each province is based on the ratio of reported national reported primary sector employment share relative to the share in Brandt and Zhu (2010) arrived at through household-level surveys. Province-specific adjustment factors would be ideal but we lack appropriate data.

${ }^{9}$ Minor adjustments are made, such as including shareholding corporation investment (post-1993) and limited liability investment (post-2005). These subcategories of investment are found in the Fixed Asset Investment Yearbooks of China.

${ }^{10} 2005$-2007 fraction is assumed identical to the 2004 fraction since this is the most recent year in the Moeller dataset. Years between 1978 and the first year of Moeller data is assumed identical to the closest available year.
} 
ing a depreciation rate of $7 \%$, the perpetual inventory method is utilized that assumes the first year for which GFCF data exists, for each province, is an equilibrium level. Investment growth rate over the life of the province is used to generate the initial capital value according to $K_{0}=I_{0} /(0.07+g)^{11}$. The 1978 capital stock is then rescaled proportionately across provinces so that the total state and non-state capital stocks equal the total national levels as determined by Brandt and Zhu (2010), and evolved forward from there using the adjusted-investment levels.

Finally, GDP statistics by sector and provinces prove the most challenging. We begin with total non-primary GDP as reported in the statistical yearbooks - deflated using the above mentioned official province-specific GDP deflator. We then assume that the fraction of non-primary GDP accounted for in each sector is identical to that sector's share of total employee payroll. Essentially, this follows the methodology of Brandt and Zhu (2010) by assuming relative output-per-worker is identical to relative wages. To perform this decomposition, an estimate of sectoral wages is constructed from official sources. ${ }^{12}$ State-sector wages are as reported until 1992, after which the broadly defined state sector wages are simply a weighted average of the state and shareholding corporation wages. Non-state sector wages are constructed from determining the total urban payroll plus total township-and-village enterprise payroll ${ }^{13}$, less the state-sector payroll, per employee in urban and TVE less state. All employment adjustments described earlier in this section are not involved in the calculation of average non-state wages.

\section{Empirical Analysis}

\subsection{Parameter Choices}

We set the labor share $a$ to 0.5, as in Brandt and Zhu (2010). There are no available estimates of $\phi$ and $\sigma$ in the literature. We choose 0.67 as the value for both parameters.

\footnotetext{
${ }^{11}$ All provinces have an initial year of 1978, except for Tibet and Chongqing, which begin in 1992 and 1996, respectively.

${ }^{12}$ Labor Statistics Yearbook of China and the Statistical Yearbook of China, for the period 1993-onwards. Total and state-sector employment, by province, for years prior to 1995 are found in China Regional Economy Statistics.

${ }^{13}$ Reported provincial TVE payroll and employment data are adjusted proportionately such that the total of the provincial data is equal to their national counterparts. Official provincial TVE payroll and employment are reported in the Township and Village Enterprise Statistics volume, which covers 1978-2004. National yearbooks provide the data for the recent years.
} 
This implies that the elasticity of substitution across provinces is 1.5 , which is the value commonly used in the international real business cycle literature and is much lower than the values that are used in the trade literature. (See, e.g., Ruhl, 2004.) We choose this low value of elasticity to be on the conservative side in our estimate of distortions. With a higher value for this elasticity (and therefore lower value for $\phi$ and $\sigma$ ), the estimated distortion in China would be larger.

\subsection{Measuring TFP by Province and Sector}

To measure distortions, we need to have measures of province-sector specific TFP $A_{i j}$ for all provinces and sectors. To measure this directly, we need to have province and sector specific deflators. However, we only have deflators by province. Furthermore, the provincial deflators are all normalized to one in 1978, which means that the real provincial GDPs may also reflect differences in prices in 1978. So, we need to adjust for both the initial provincial price differences and the sectoral price differences in each year. Let $Y_{i j}^{\text {measured }}(t)$ and $Y_{i j}(t)$ be the measured and actual real GDP for province $i$ and sector $j$ in year $t$. Then, we have

$$
Y_{i j}^{\text {measured }}(t)=\frac{P_{i j}(t) Y_{i j}(t)}{\left(P_{i}(t) / P_{i}(1978)\right)}
$$

So,

$$
Y_{i j}(t)=\frac{Y_{i j}^{\text {measured }}(t)}{\left(P_{i j}(t) / P_{i}(t)\right) P_{i}(1978)} .
$$

Using a method similar to Hsieh and Klenow (2009), we infer the price information from nominal GDP shares. With the CES aggregate production functions, it can be shown that the prices satisfy the following equations:

$$
P_{i j}(t) / P_{i}(t)=\left(\frac{Y_{i j}^{\text {nominal }}(t)}{Y_{i s}^{\text {nominal }}(t)+Y_{i n}^{\text {nominal }}(t)}\right)^{-\frac{\phi}{1-\phi}}
$$

and

$$
P_{i}(1978) / P(1978)=\left(\frac{Y_{i}^{\text {nominal }}(1978)}{Y^{\text {nominal }}(1978)}\right)^{-\frac{\sigma}{1-\sigma}}
$$

Here, $P(1978)$ and $Y^{\text {nominal }}(1978)$ are the national price index and nominal GDP, respectively. We normalize the national price index in 1978 to one. Then, we can calculate the 
real GDP in the following way ${ }^{14}$ :

$$
Y_{i j}(t)=Y_{i j}^{\text {measured }}(t)\left(\frac{Y_{i j}^{\text {nominal }}(t)}{Y_{i s}^{\text {nominal }}(t)+Y_{i n}^{\text {nominal }}(t)}\right)^{\frac{\phi}{1-\phi}}\left(\frac{Y_{i}^{\text {nominal }}(1978)}{Y^{\text {nominal }}(1978)}\right)^{\frac{\sigma}{1-\sigma}}
$$

Figure 5 shows non-agricultural TFP of the state and the non-state sectors for each of the 27 provinces. As can be seen, the TFP levels in the non-state sector are generally higher than those in the state sector and the gaps have increased over time. There are also significant differences in TFP across provinces. Given these differences, it is clear that the allocation of capital and labor across provinces and sectors has important impacts on the aggregate TFP.

\subsection{The Evolution of Factor Market Distortion Over Time}

We now examine the impact of misallocation of factors on aggregate TFP. Figure 7 plots the actual and efficient aggregate TFP, $A$ and $A^{*}$, respectively. Throughout the period between 1985 and 2007, there is a persistent and significant gap between the actual and efficient TFP, suggesting that there has been persistent misallocation of factors in China. The gap narrowed in the first decade or so, but widened afterwards. Tables 1 shows the growth rates of the efficient and actual TFPs for the entire period and two sub-periods, 1985-1997 and 1997-2007. Between 1985 and 1997, the actual annual TFP growth rate was $0.96 \%$ higher than the growth rate of the efficient TFP. In other words, there were improvements in factor allocation in the first sub-period and their contribution to aggregate TFP growth was nearly one percent a year. In the last decade, however, the average annual growth rate of the actual TFP was $1.41 \%$ lower than that of the efficient TFP, implying that overall factor market distortions increased during the last decade, more than offsetting all the efficiency gains from reduced distortion in the first sub-period.

\subsection{Evaluating the Impacts of Within- and Between-Province Dis- tortions}

Next, we investigate the impacts of different types of distortions on the aggregate TFP by conducting a series of counterfactual experiments in the model presented in Section 3.

\footnotetext{
${ }^{14}$ Note that when $\phi=\sigma=0$, the case of perfect substitution, the actual GDP is simply the measured GDP and therefore, the measured TFP is also the actual TFP. For the cases of imperfect substitution, however, the two are not the same.
} 
To evaluate the impact of within-province distortions in capital allocation, for example, we conduct a counterfactual experiment in the model by setting the capital taxes of both the state and non-state to the average tax of the two sectors within each province. We then compare the resulting measure of the aggregate distortion to the original measure. The difference can be interpreted as the contribution of the within-province misallocation of capital on aggregate TFP.

The counterfactual experiments that we conduct are listed below:

- No within-province distortion:

- No within-province distortion in capital allocation: Eliminating the within-province difference in capital returns by equalizing the taxes between the state and the nonstate sector for capital only.

- No within-province distortion in labor allocation: Eliminating the within-province difference in labour returns by equalizing the taxes between the state and the nonstate sector for labour only.

- No between-province distortion:

- No between-province product market distortion: Eliminating the cross-province differences in output taxes.

- No between-province distortion in capital allocation: Eliminating the cross-province differences in capital taxes.

- No between-province distortion in labour allocation: Eliminating the cross-province differences in labour taxes.

Figure 8plots our measures of actual distortion and the distortions when we eliminiate all within-province disotortions and all between-province distortions, respectively. The overall distortion declines in the first half of the period and then increases in the second half. Eliminating either within-province or between province distortions results in a significant reduction in the overall distortion. However, eliminating the between province distortions does not change the time trend of the overall distortion. In contrast, elminating withinprovince distortions leaves the aggregate distortion relatively flat over time, suggesting that the changes in aggregate distortion over time were mainly due to changes in within-province distortions. Figure 9displays the contribution of between and within-province distortions over time. 


\subsubsection{Experiments with No Within-Province Distortion}

Distortions within a province take the form of labor or capital market distortions between the state and nonstate sectors. Figures 10 display these distortions over time by plotting the percentage difference between efficient and actual TFP. Removing the capital market distortions within each province lowers the distortion to half its original value for 2007. Furthermore, the counterfactual level of aggregate distortions would have been relatively constant rather than increasing rapidly in the last decade. This implies that the rising cost of distortions in the last decade was mainly due to the worsening in capital allocation between the state and the non-state sectors. In contrast, shutting down the labour market distortions has almost no impact on the aggregate TFP and overall distortions.

\subsubsection{Experiments with No Between-Province Distortion}

Figures 10 plots the aggregate distortion measure under three scenarios: no distortion in capital allocation, labour allocation, or product market across provinces within each sector. In contrast to the within province results, the between province capital market distortion has little impact on aggregate TFP. Between province labour markets, however, contribute nearly ten percentage points to the $45 \%$ gap between efficient and actual TFP in 2007 and is fairly constant through time. The product market distortion has similar, though slightly smaller, impact. Overall, none of the between province distortions seems to be worsening or improving through time. As a comparision, we use the same method to measure the between-state distortions in the US and plot the measures over time in Figure 12.

\subsection{Discussion}

Perhaps the most important result from our empirical analysis above is regarding the misallocation of capital between the state and non-state sectors. This distortion accounts for half of the overall impact of distortions on aggregate TFP and, more important, almost all the time variation in the impact of distortions. What drives the changes in capital market distortion? In particular, why has the distortion increased in the last decade? Here we provide some preliminary evidence showing that it may be a product of the Chinese government's regional policies.

Figure 13 shows the average output per worker for China's four geographical regions: East, Middle, Northeast and West. In 1997, among the four regions, the Eastern region, 
which includes all the coastal provinces, had the highest labor productivity and the Western region's labor productivity was the lowest. Around that time, many economists and policy makers argued that this disparity in performance was mainly due to the central government's preferential policies towards the Eastern provinces that allowed these provinces to attract more investment. To reduce the disparity, it was argued, the central government should adopt policies that would direct more investment to Western provinces, which had the lowest labor productivity among the four regions. Thus, a policy initiative called Develop the Great West was introduced by the central government in the late 1990s.

In reality, was the lack of development in the Western region a result of capital scarcity? The answer is no. Figure 14 shows that the Western region actually had the highest capitaloutput ratio among the four regions. The Develop the Great West policy worked in one aspect: significantly higher Western capital-output ratio between 1997 and 2007. However, it failed to accomplish its stated objective of reducing regional income disparity: Between 1997 and 2007, the disparity in labor productivity between the Western and Eastern regions increased, not decreased. Why the increase in disparity despite the increase in capital intensity in the West? Because most of the increased investment was directed to the region's state sector, which had much lower TFP than that of the non-state sector. (See Figure 15 and 16 for TFP and capital-output ratio by sector and region.) Thus, misallocation of capital between the state and the non-state sector worsened as as result of the regional development policy. Table 2 shows the average impact of the increased within-province misallocation of capital on provincial TFP for the four regions during the period of 1997-2007. Within-province misallocation of capital had the largest negative impact on TFP growth in the Western region, reducing potential TFP growth rate by $1.63 \%$ a year.

\section{Conclusion}

In this paper, we examine the impact of the misallocation of resources across provinces and sectors (state versus non-state) on aggregate TFP. Despite significant increases in factor mobility, our analysis suggests that China continues to suffer high costs arising from factor market distortions. Even as late as 2007, these distortions were lowering aggregate TFP by a third; alternatively, aggregate TFP would increase by a half without these distortions.

Within province distortions arising from the favored treatment of the state-sector vis-a-vis the non-state are most important. After declining during the first decade and a half of 
reform, these distortions have increased significantly since 1997. There is also a marked "regional" dimension to them, with the distortions and their costs more severe in the central and western provinces. A case can be made that much of this is related to the central government's efforts to redistribute resources to these provinces through a highly inefficient state sector. With the opportunities for future increases in output on the extensive margin narrowing rapidly, these costs on aggregate TFP are likely to take on added importance. 


\section{References}

[1] Alfaro, Laura; Andrew Charlton and Fabio Kanczuk (2008). "Plant-Size Distribution and Cross-Country Income Differences," NBER Working Papers 14060.

[2] Bai, Chong-En; Hsieh, Chang-Tai and Qian, Yingyi (2006) "The Returns to Capital in China." Brookings Papers on Economic Activity. 37(2): 61-102.

[3] Bartelsman, Eric J., John Haltiwanger and Stefano Scarpetta, 2008. "Cross Country Dierences in Productivity: The Role of Allocative Eciency," mimeo.

[4] Boyreau-Debray, Genevieve and Wei, Shang-Jin (2005) "Pitfalls of a State-dominated Financial System: The Case of China?" NBER Working Paper No.11214.

[5] Brandt, Loren and Zhu, Xiaodong (2010) "Accounting for China's Growth." University of Toronto Working Paper.

[6] Chan, Kam Wing; Henderson, J. Vernon and Tsui, Kai Yuen (2009) "Spatial Dimensions of Chinese Economic Development." in Loren Brandt and Thomas G. Rawski ed. China's Great Economic Transformation. Cambridge University Press: New York.

[7] Dollar, David and Wei, Shang-Jin (2007) "Das (Wasted) Kapital: Firm Ownership and Investment Efficiency in China." NBER Working Paper No.13103.

[8] Gollin, Douglas, Stephen L. Parente and Richard Rogerson, 2004. "Farm Work, Home Work, and International Productivity Differences." Review of Economic Dynamics, Elsevier for the Society for Economic Dynamics, vol. 7(4), pages 827-850, October.

[9] Gong, Liutang and Xie, Danyang (2006) "Factor Mobility and Dispersion in Marginal Products: A Case on China." Frontiers of Economics in China 1: 1-13.

[10] Guner, Nezih, Gustavo Ventura and Yi Xu, 2008. "Macroeconomic Implications of Size Dependent Policies," Review of Economic Dynamics, 11(4), 721-744.

[11] Holz, Carsten (2009) "No Razo's Edge: Reexamining Alwyn Young's Evidence for Increasing Inter-Provincial Trade Barriers in China." Review of Economics and Statistics, no.3: 599-616.

[12] Hsieh, Chang-Tai and Klenow, Peter (2009) "Misallocation and Manufacturing TFP in China and India." Quaterly Journal of Economics, Vol. 124 (4): 1403-48. 
[13] Poncet, Sandra (2003) "Measuring Chinese Domestic and International Integration." China Economic Review, 14(1): 1-21.

[14] Restuccia, Diego and Richard Rogerson, 2008. "Policy Distortions and Aggregate Productivity with Heterogeneous Plants," Review of Economic Dynamics, 11(4), 707-720.

[15] Restuccia, Diego \& Yang, Dennis Tao \& Zhu, Xiaodong, 2008. "Agriculture and aggregate productivity: A quantitative cross-country analysis," Journal of Monetary Economics, Elsevier, vol. 55(2), pages 234-250, March.

[16] Ruhl, Kim J. (2004) "The International Elasticity Puzzle." New York Stern School of Business.

[17] Vollrath, Dietrich, 2009. "How important are dual economy effects for aggregate productivity?" Journal of Development Economics, Elsevier, vol. 88(2), pages 325-334, March

[18] Young, Alwyn (2000) "The Razor's Edge: Distortions and Incremental Reform in the People's Republic of China." Quaterly Journal of Economics, Vol. 115(4): 1091-1135.

[19] Zhang, Xiaobo and Tan, Kong-Yam (2007) "Incremental Reform and Distortions in China's Product and Factor Markets." World Bank Economic Review 21(2): 279-299. 
Table 1: TFP Growth Rates, Efficient and Actual

\begin{tabular}{cccc}
\hline Period & $1985-2007$ & $1985-1997$ & $1997-2007$ \\
\hline \hline Efficient & $4.69 \%$ & $4.43 \%$ & $5.01 \%$ \\
Actual & $4.58 \%$ & $5.39 \%$ & $3.60 \%$ \\
\hline $\begin{array}{c}\text { Impact of Distortion : } \\
\text { Actual-Efficient }\end{array}$ & $-0.11 \%$ & $0.96 \%$ & $1.41 \%$ \\
\hline
\end{tabular}

Table 2: Average TFP Growth Rates by Region

\begin{tabular}{ccccc}
\hline Period & \multicolumn{4}{c}{$1997-2007$} \\
& East & Middle & Northeast & West \\
\hline \hline Actual & $3.90 \%$ & $3.71 \%$ & $4.39 \%$ & $2.48 \%$ \\
No Within-Province Distortion & $4.85 \%$ & $5.17 \%$ & $5.98 \%$ & $4.10 \%$ \\
\hline Impact of Distortion: & & & & \\
Change on TFP & $-0.95 \%$ & $-1.46 \%$ & $-1.59 \%$ & $-1.63 \%$ \\
\hline
\end{tabular}


Figure 1:

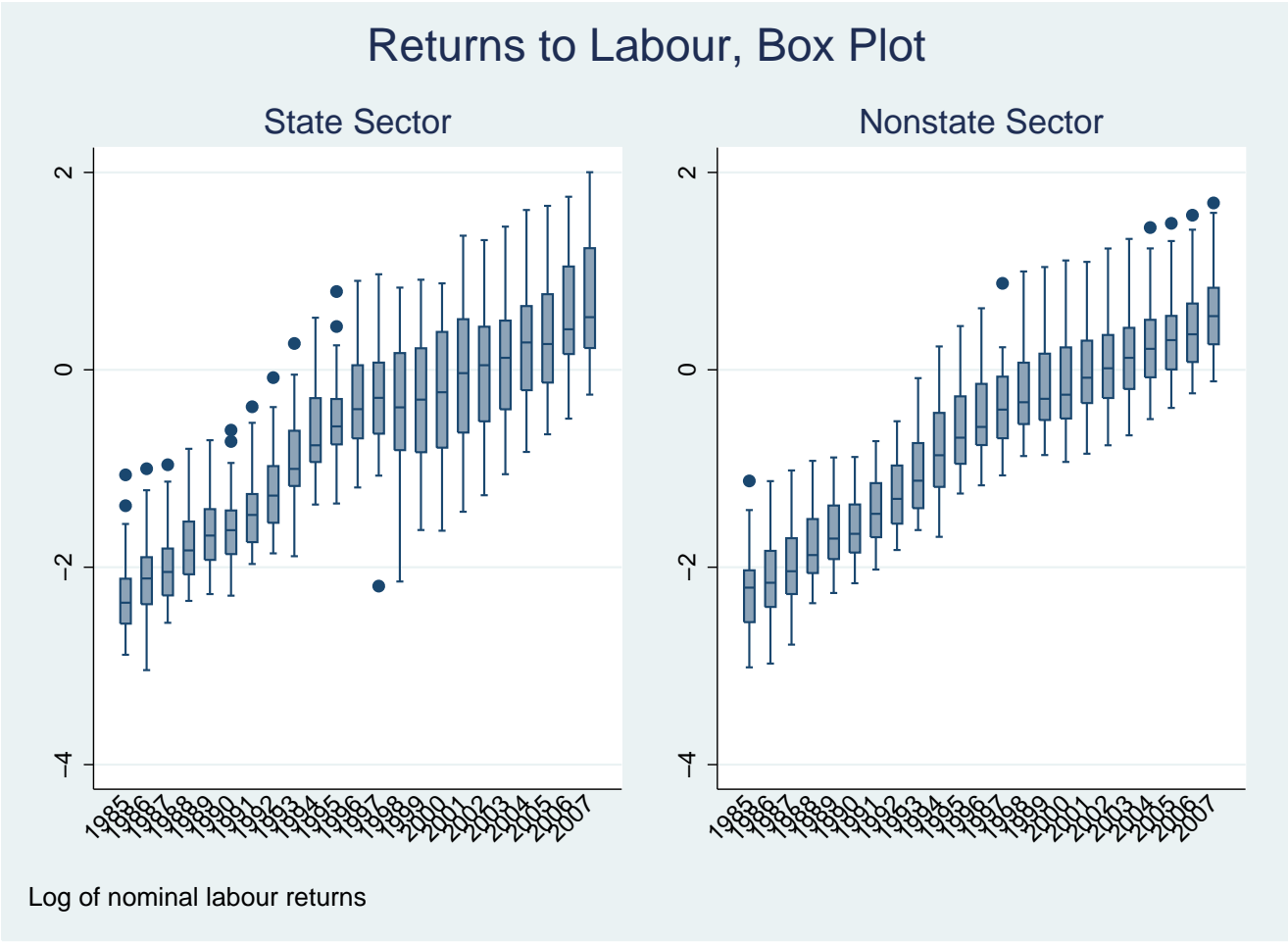

Figure 2:

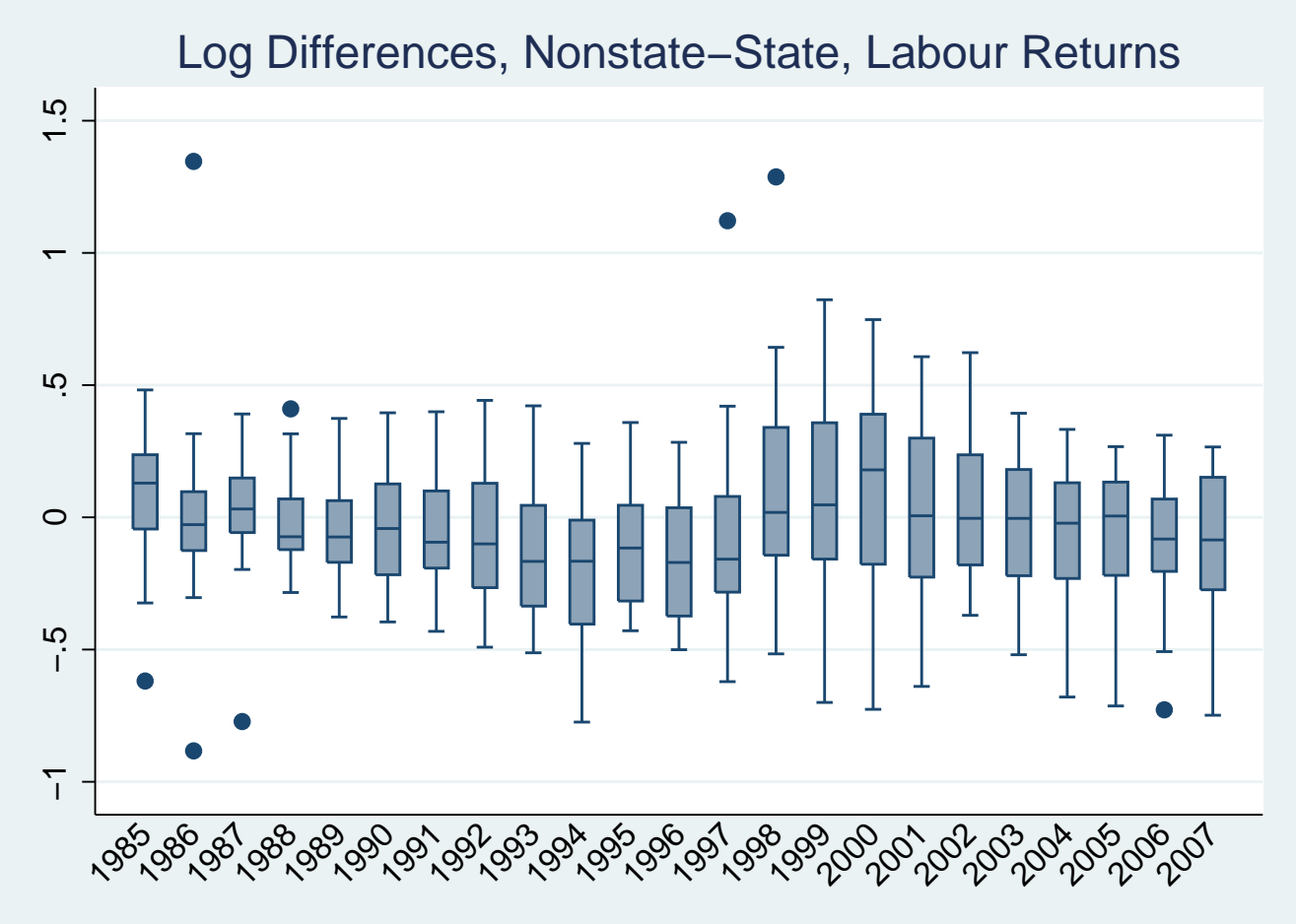


Figure 3:

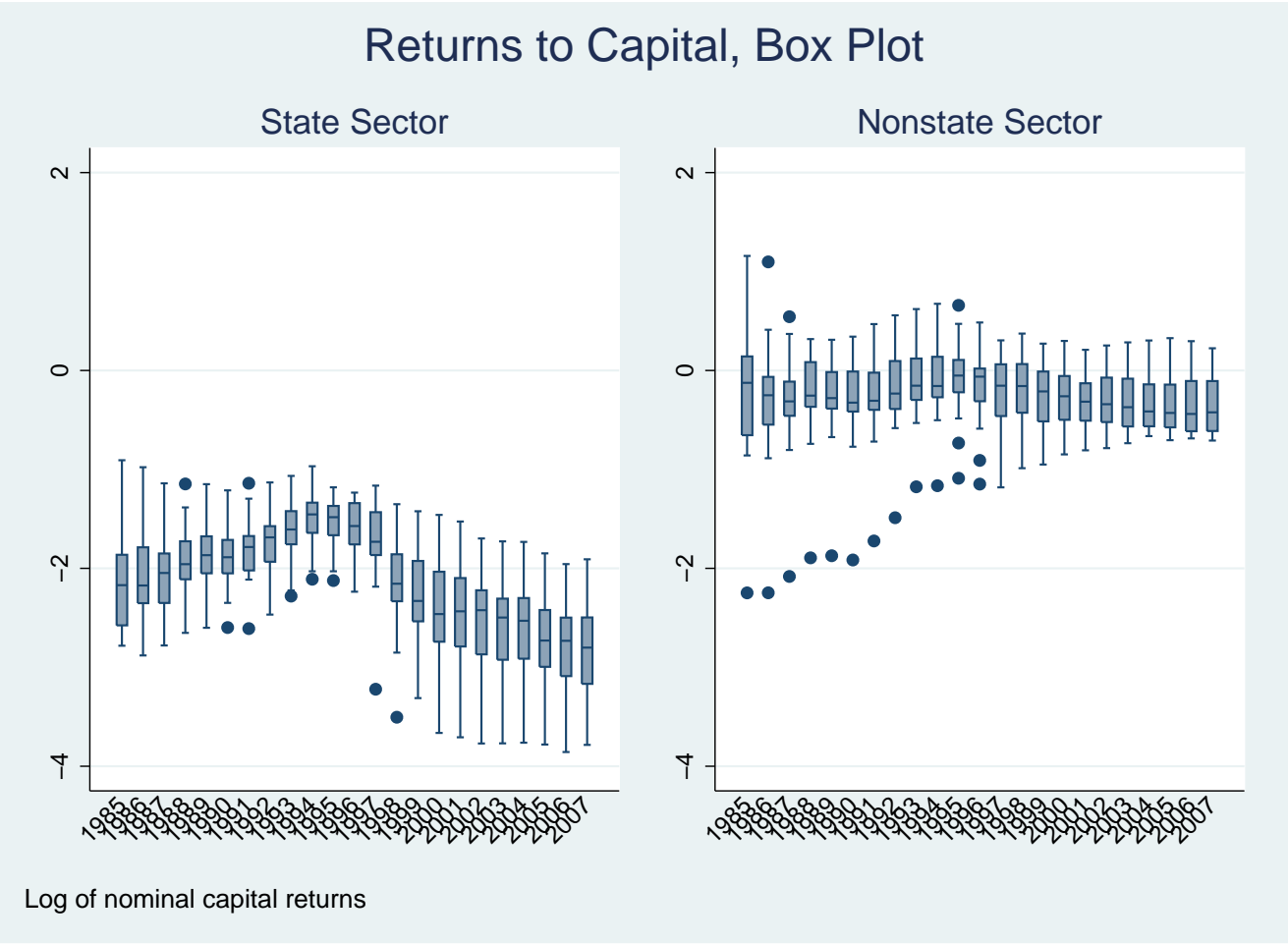

Figure 4:

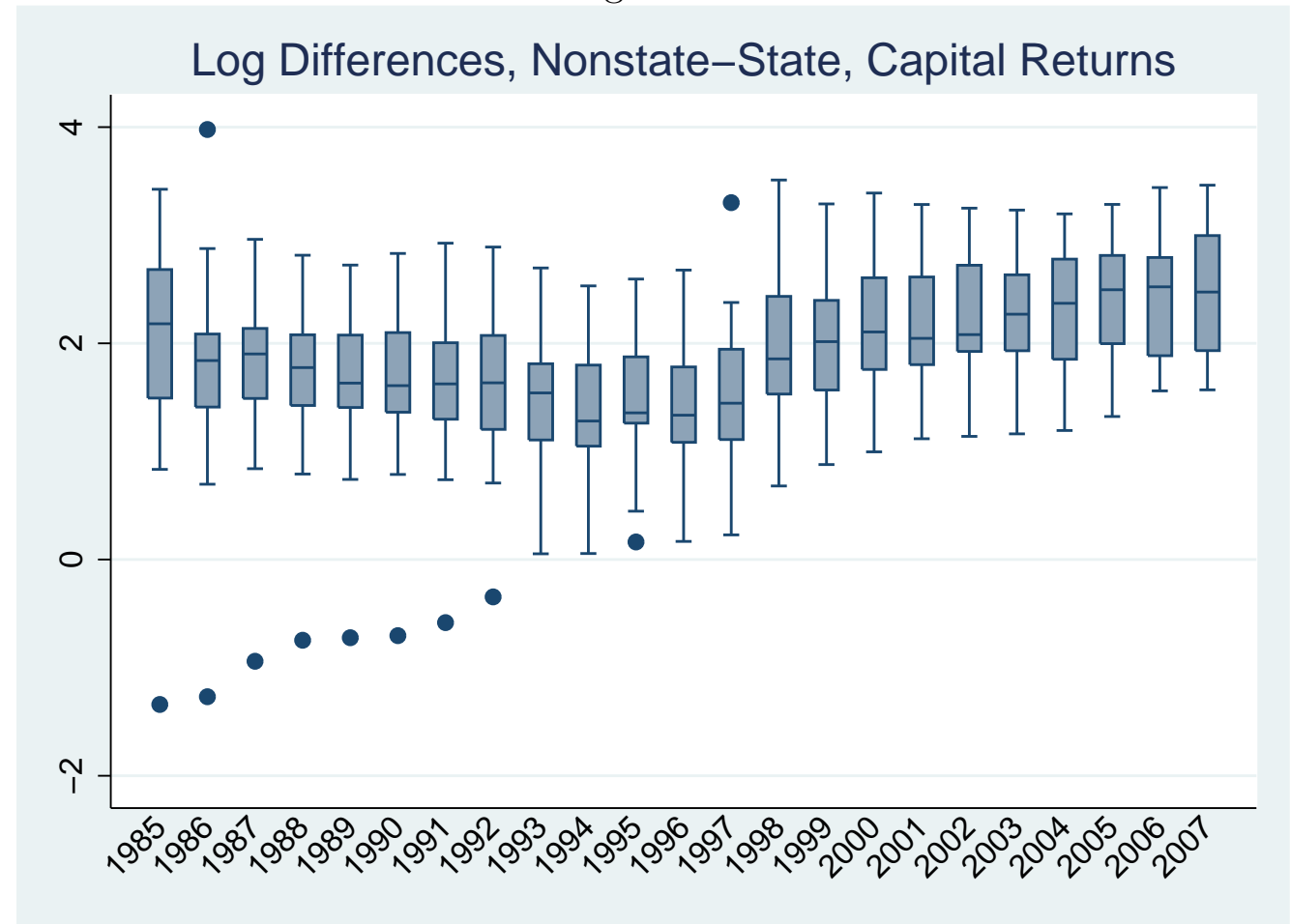


Figure 5:

\section{TFP, Box Plot}
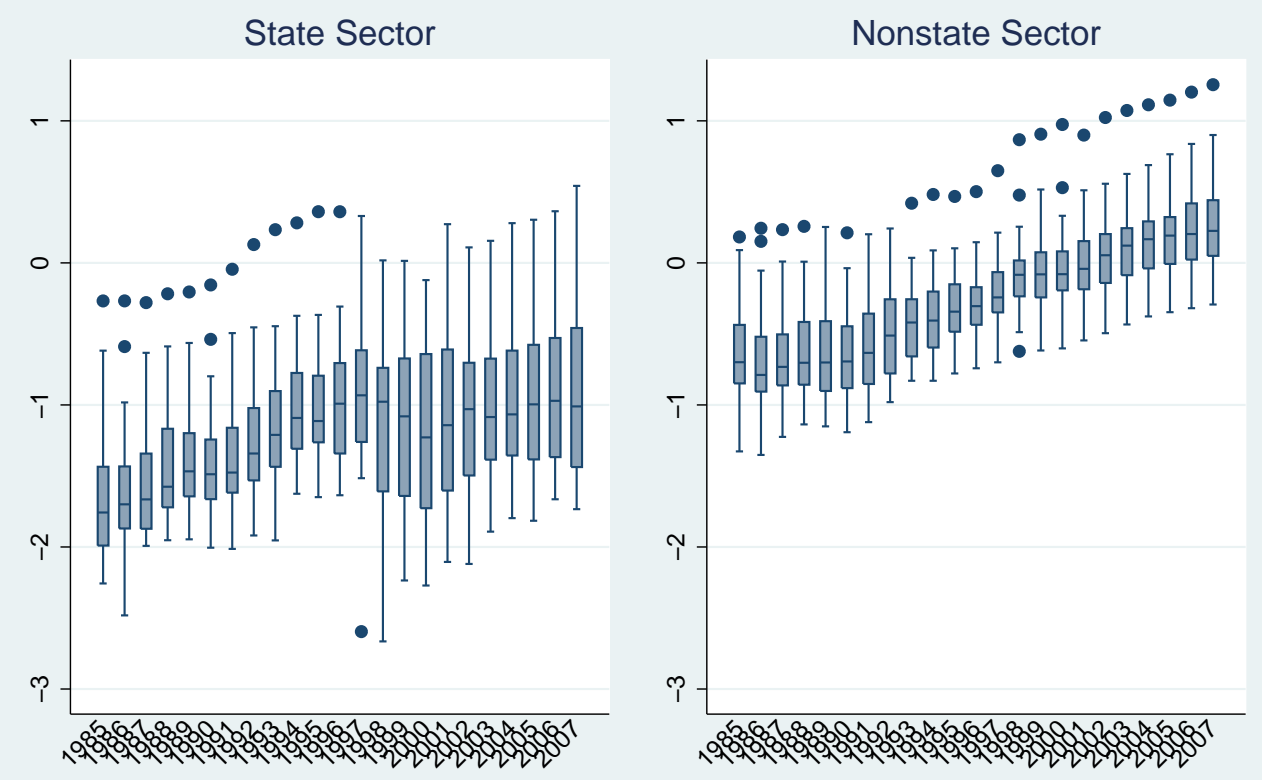

Log of total factor productivity

Figure 6:

Log Differences, Nonstate-State, Total Factor Productivity

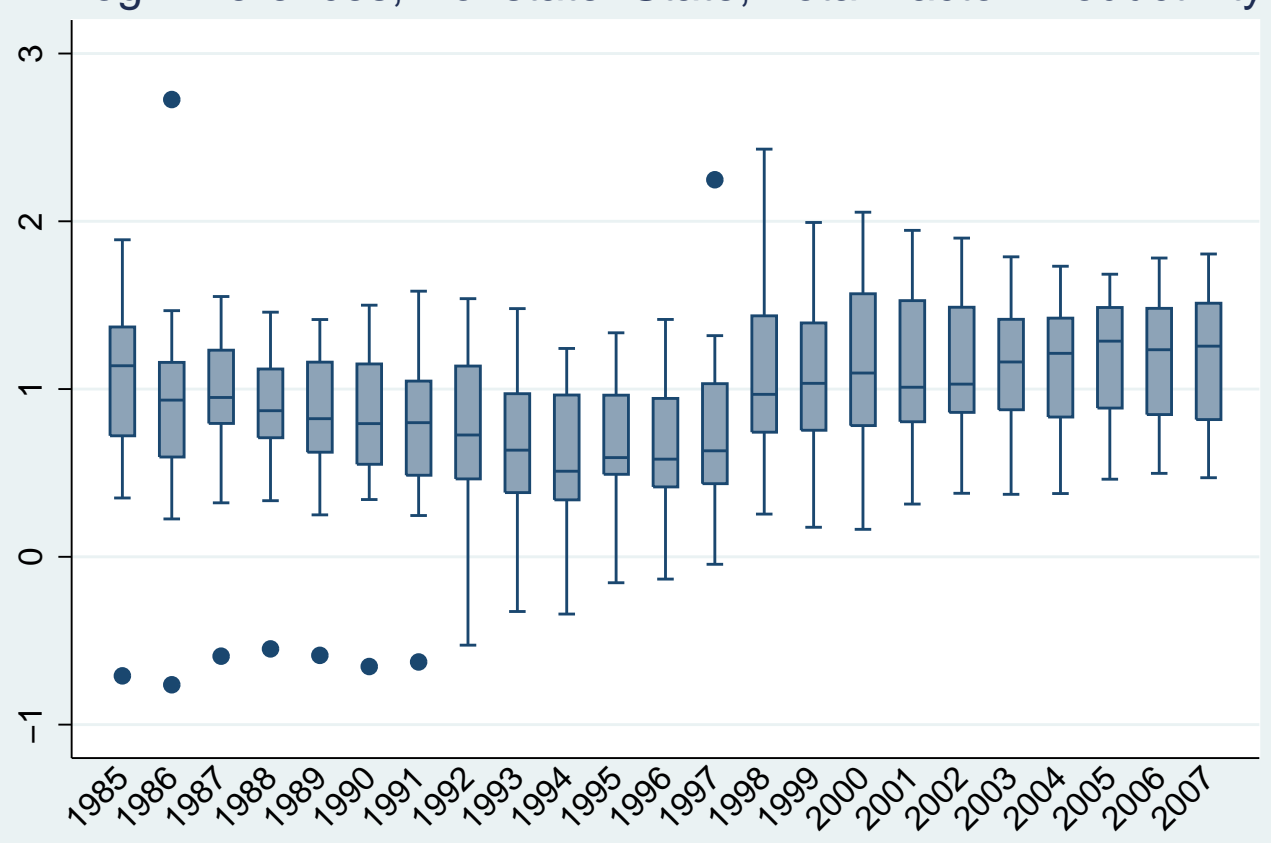


Figure 7:

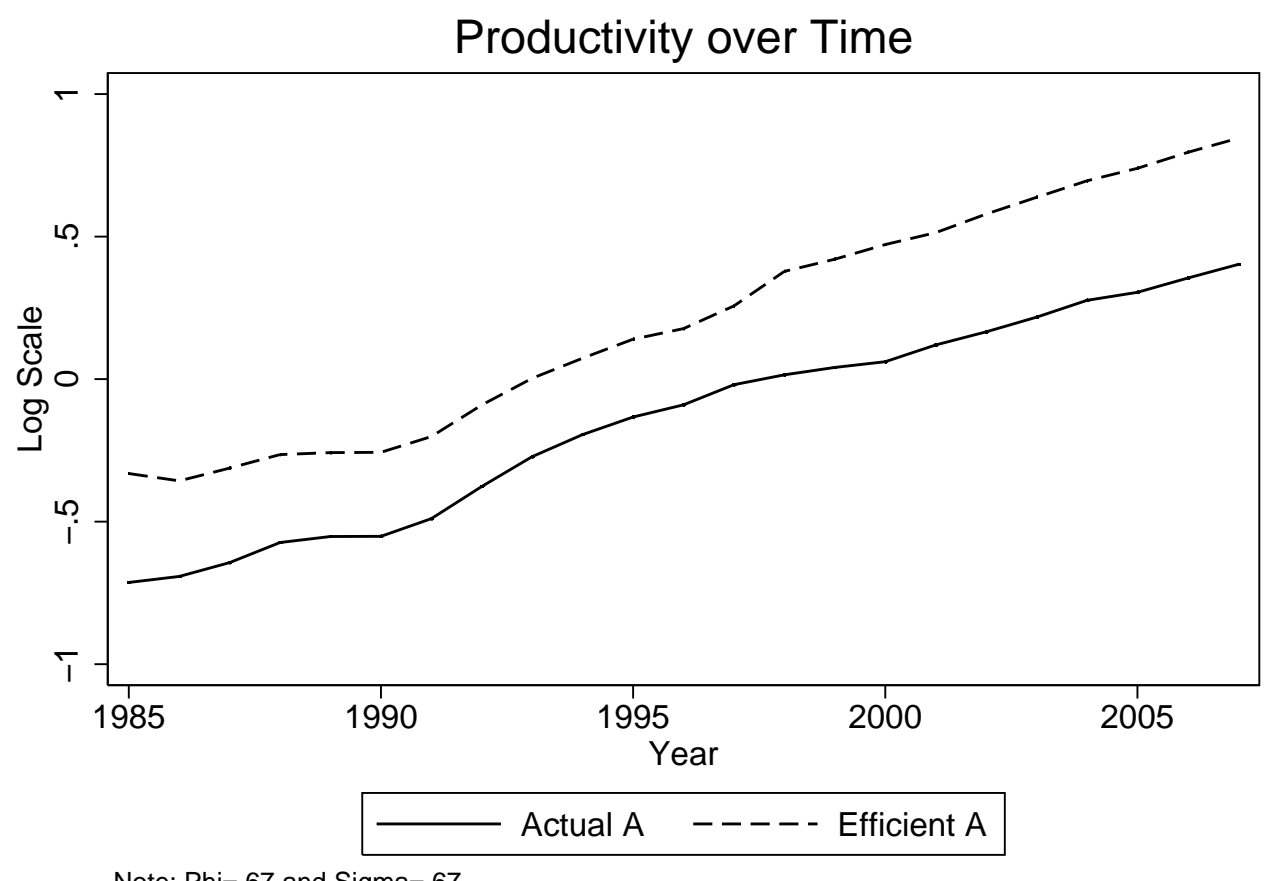

Note: $\mathrm{Phi}=.67$ and Sigma $=.67$ 
Figure 8:

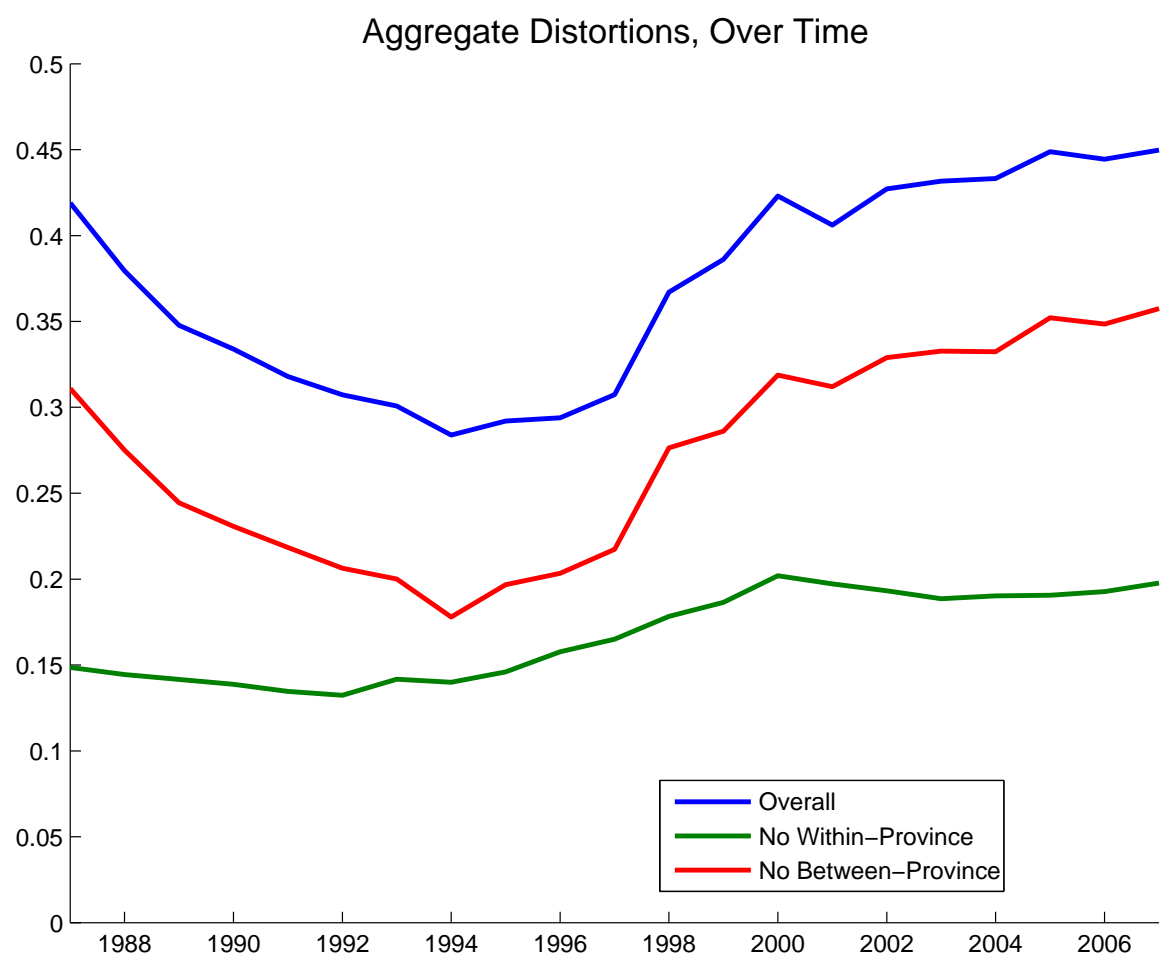

Figure 9:

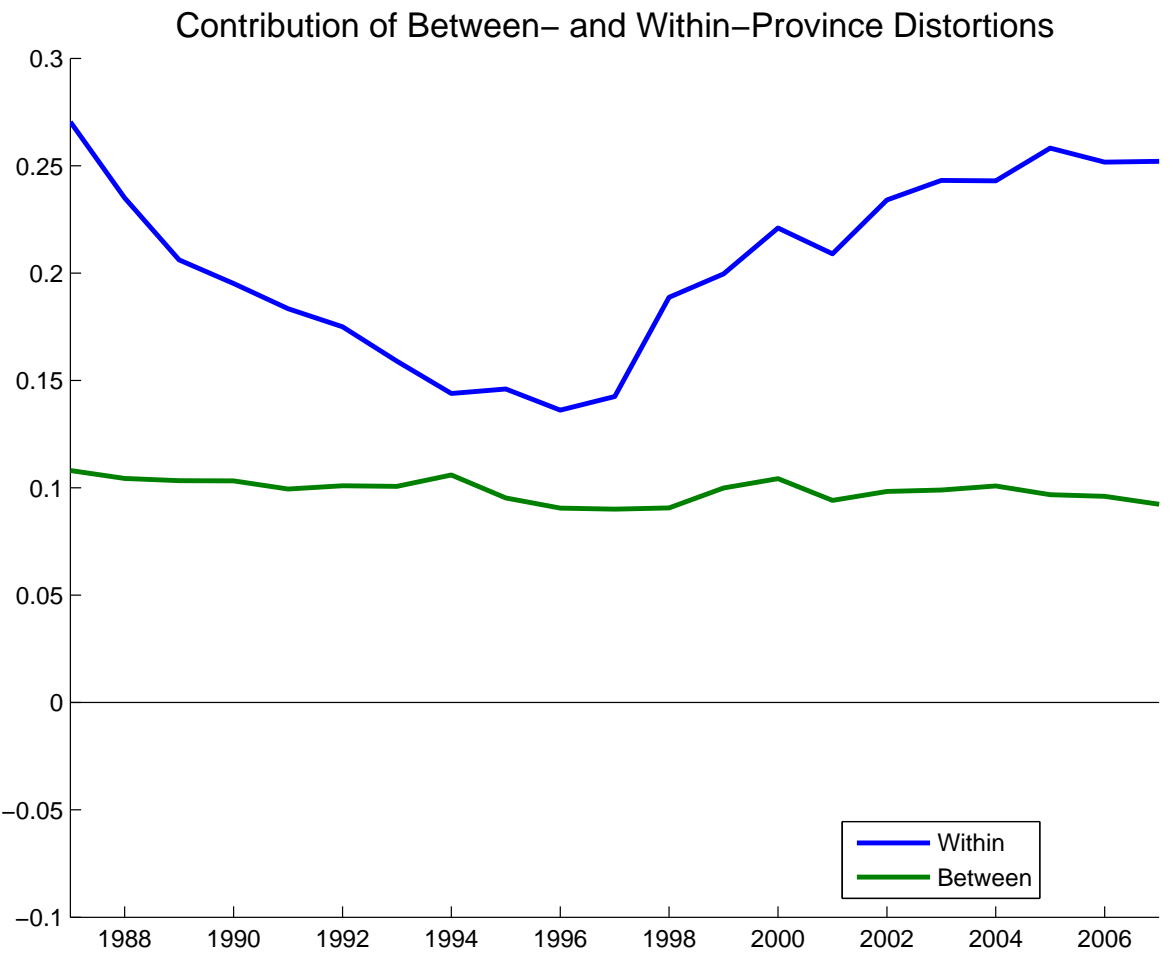


Figure 10:

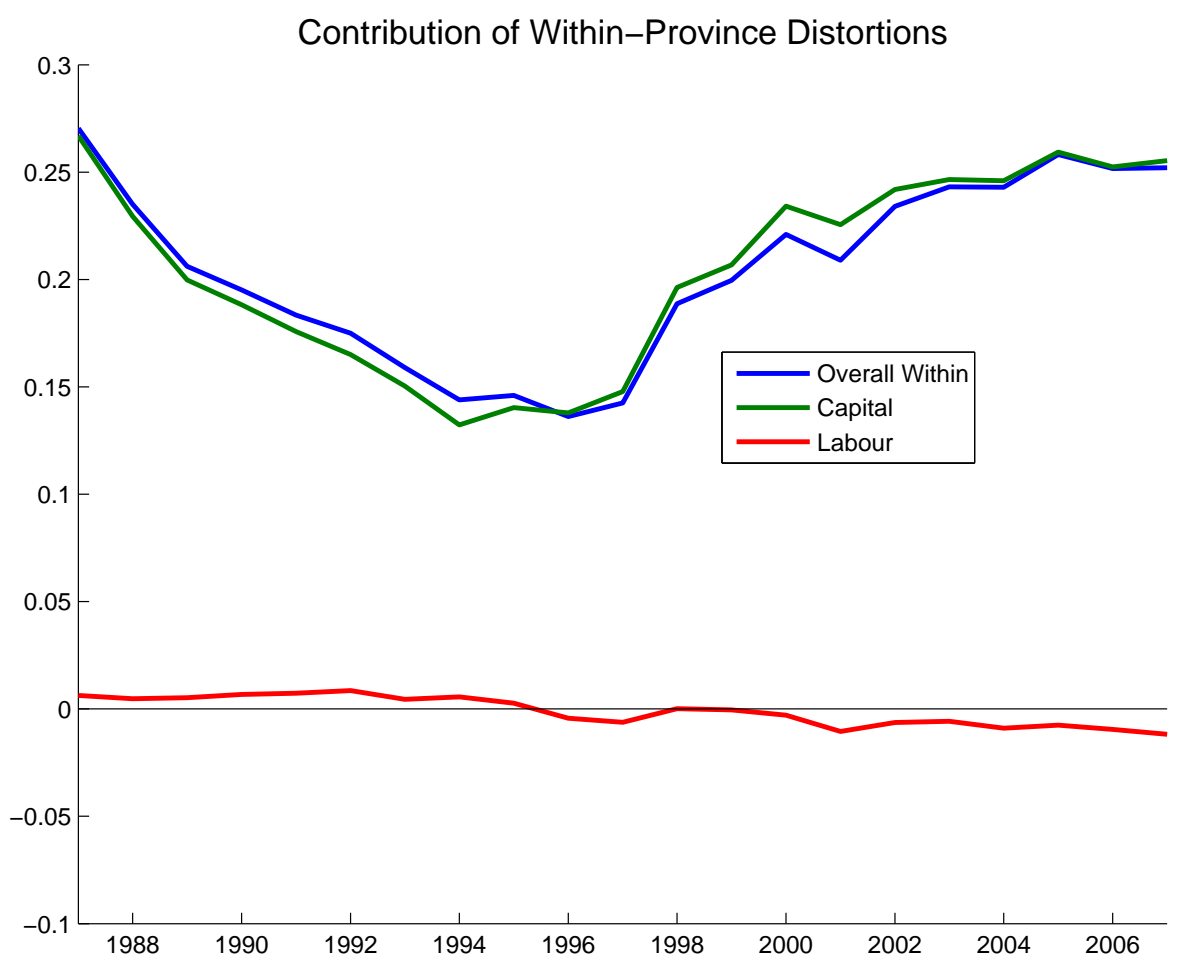

Figure 11:

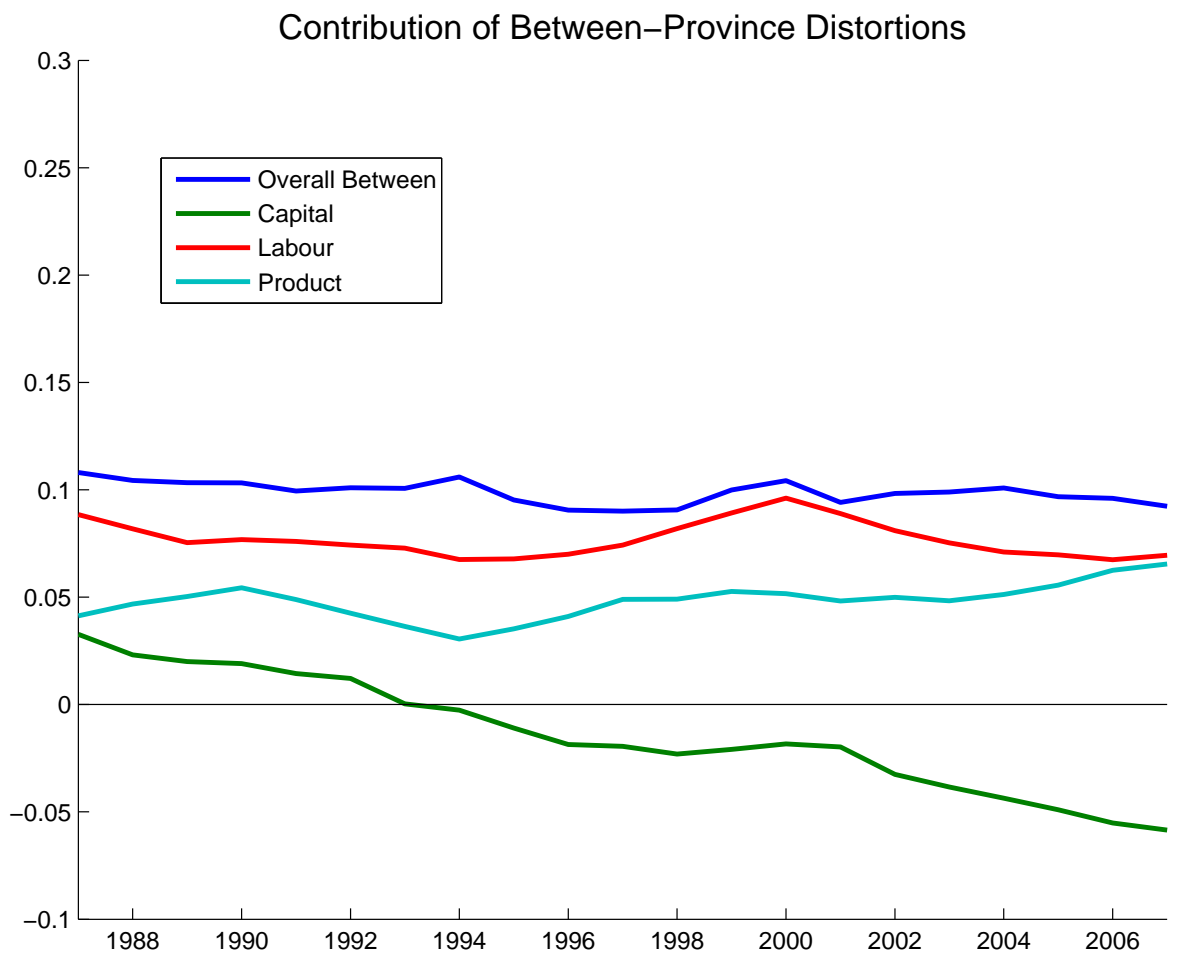


Figure 12:

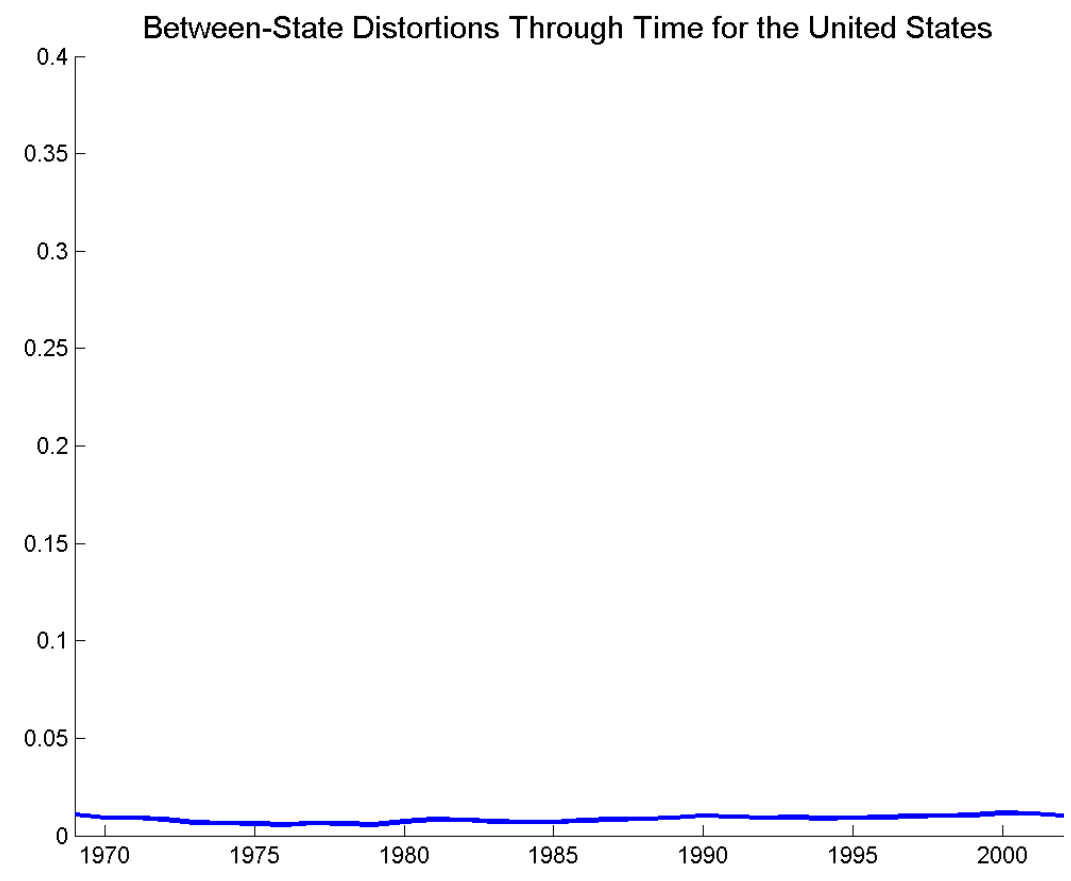

Figure 13:

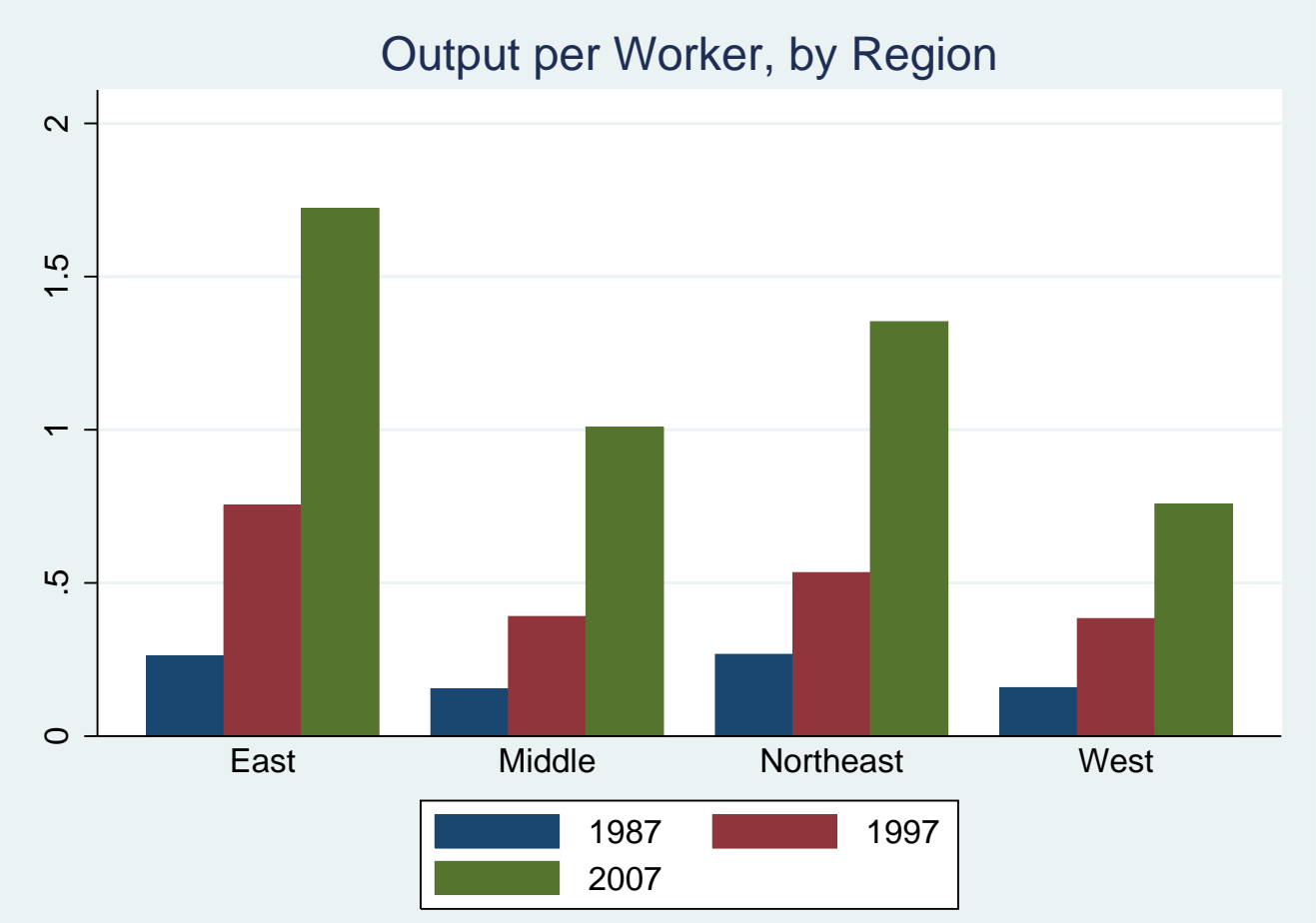


Figure 14:

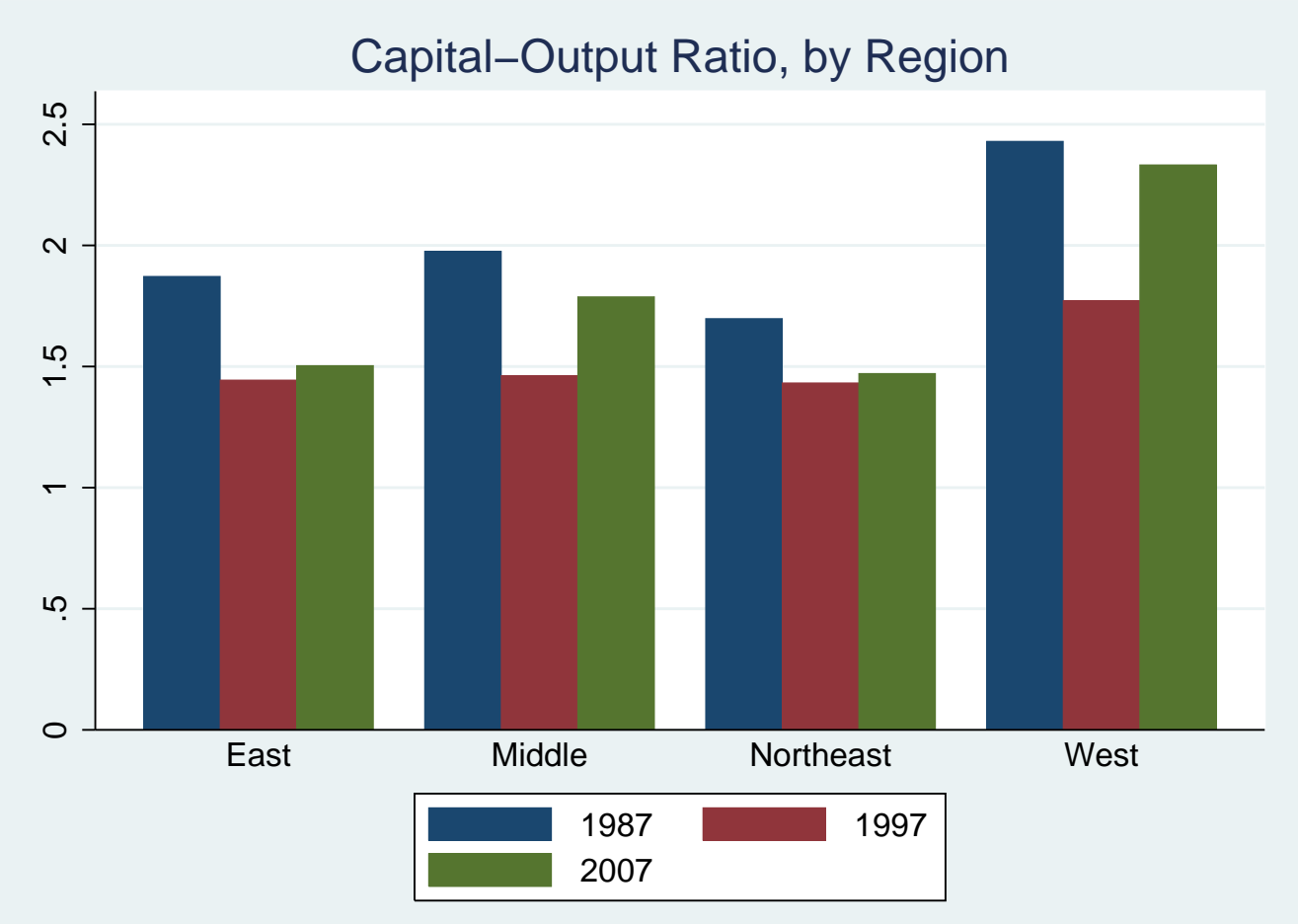

Figure 15:

Total Factor Productivity, by Region
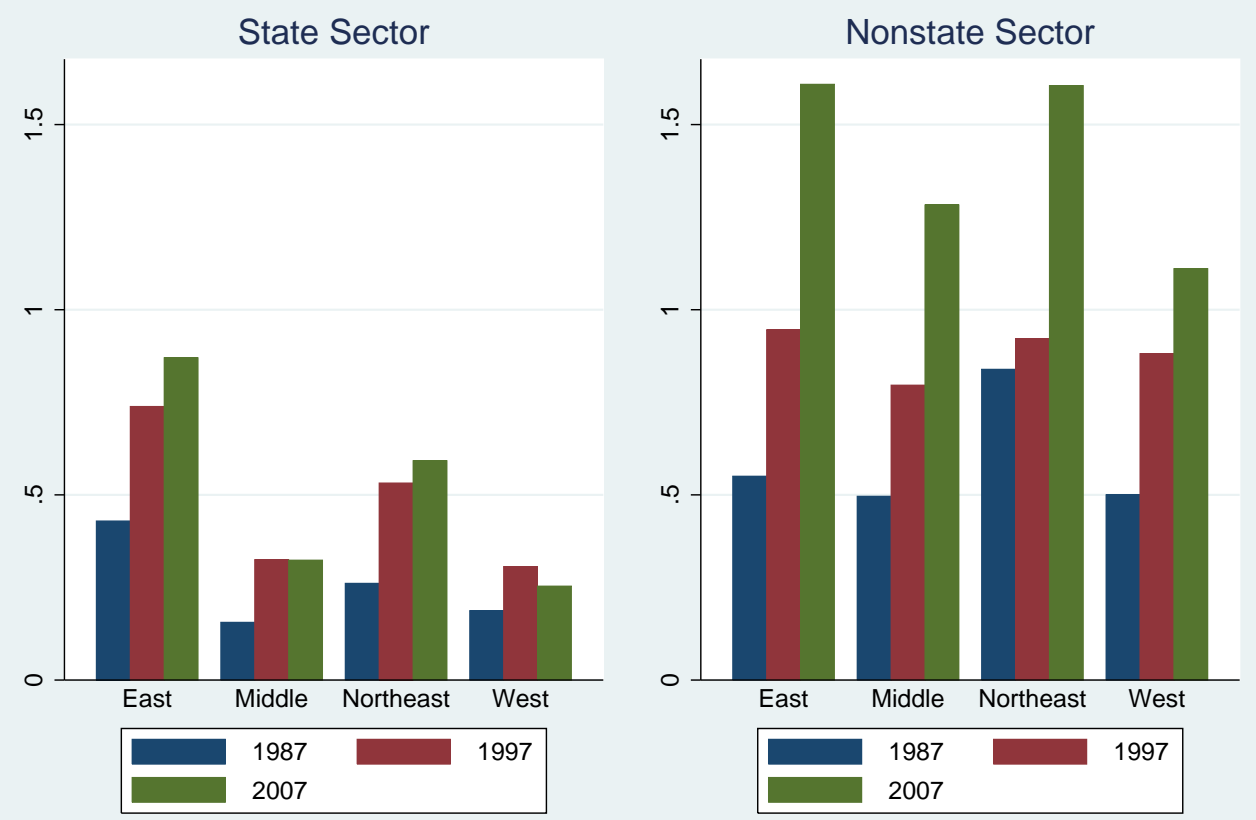
Figure 16:

\section{Capital Output Ratio, by Region}

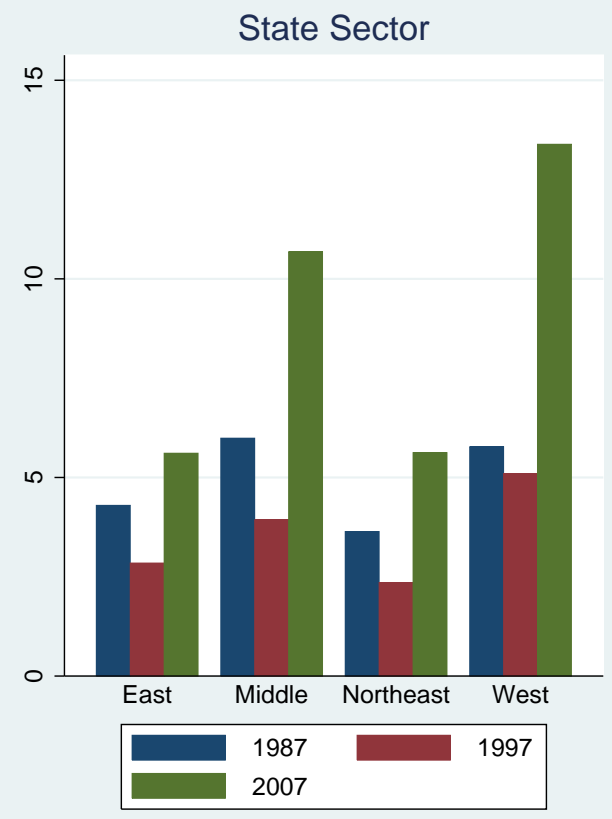

Nonstate Sector

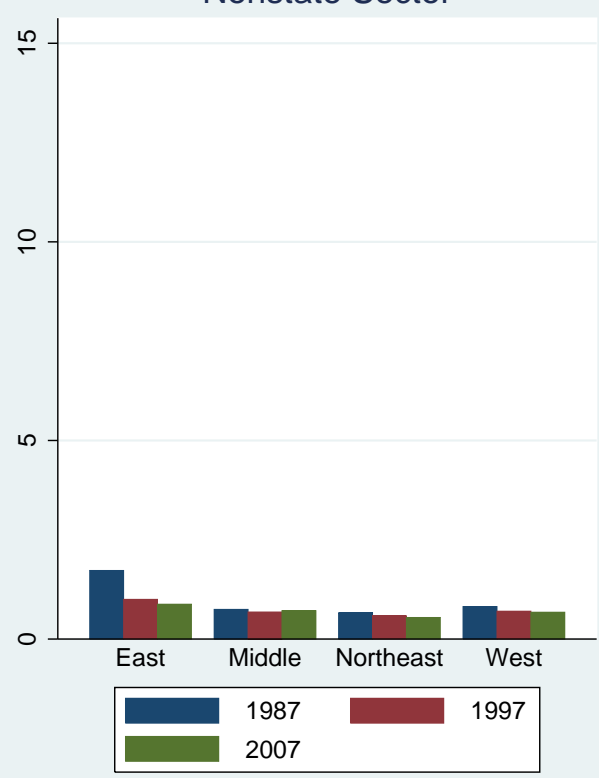

